\section{DAS DEMANDAS AO DOM: AS CRIANÇAS PAIS DE SEUS PAIS}

From Demands to the Gift: Children Parents of their Parents

De las Búsquedas al Don: Los Niños Padres de sus Padres

Des Demandes au Don: Les Enfants Pères de leurs Parents

\section{Resumo}

Tomando como temas centrais os processos de maturação infantil e o exercício da parentalidade, o presente trabalho se propõe a investigar a experiência da criança que adota uma postura parental diante dos adultos importantes para o seu existir. Parte-se da investigação sobre o conceito de parentalização - uma ampliação da compreensão do contexto familiar de inversão geracional entre pais e filhos - a fim de refletir sobre as principais repercussões deste processo no desenvolvimento emocional infantil. Constata-se que a parentalização se apresenta como um risco para a saúde psíquica da criança quando se consolida como via privilegiada da relação entre pais e filhos.

Palavras-chave: desenvolvimento emocional; maturação infantil; parentalidade; parentalização; psicanálise.

\section{Abstract}

Taking as its central themes the children's maturation process and the exercise of parenting, this study aims to investigate the child's experience that takes a parental attitude toward the important adults for their existence. From the research on the concept of parentification an expansion of the understanding of the family context of generational reversal between parents and children - in order to reflect on the major impact of this process on children's emotional development. It appears that the parentification presents itself as a risk to the mental health of the child when it consolidates as a privileged means of relationship between parents and children.

Keywords: emotional development; children's maturity; parenthood; parentification; psychoanalysis.

\section{Resumen}

Tomando por temas centrales los procesos de maduración infantil y el ejercicio parental, el presente trabajo propone investigar la experiencia del niño que adopta una postura parental ante los adultos importantes para su existir. El punto de partida es en la investigación del concepto de "parentalización" - una ampliación del entendimiento acerca del contexto familiar de inversión de generación entre padres e hijos - para reflexionar acerca de las principales repercusiones de este proceso en el desarrollo emocional infantil. Se constata que la "parentalización" se presenta como un riesgo a la salud psíquica del niño cuando consolidada como privilegiada vía de la relación entre padres e hijos.

Palabras clave: desarrollo emocional; maduración infantil; parental; "parentalización";

\section{Artigo Original}

1) Pós-doutoranda em Psicologia Clínica pela Pontifícia Universidade Católica do Rio de Janeiro, Doutora em Teoria Psicanalítica pela Universidade Federal do Rio de Janeiro, com período sanduíche na Université Paris Diderot (Paris 7).

2) Professora Titular do Departamento de Psicologia da Pontifícia Universidade Católica do Rio de Janeiro, Coordenadora do Curso de Especialização em Psicoterapia de Família e Casal da PUCRio.

3) Professora Assistente do Departamento de Psicologia da Pontifícia Universidade Católica do Rio de Janeiro. 
psicoanálisis.

\section{Résumé}

Ayant comme thèmes principaux les processus de maturité des enfants et l'exercice de la parentalité, cet article propose étudier l'expérience de l'enfant qui a un comportement parental devant les adultes importants à son existence. On part de l'investigation autour du concept de parentalisation - une extension de l'entente du contexte familier d'inversion générationelle entre des parents et des enfants - pour faire réfléchir sur les principaux répercussions de ce processus dans le développement émotionel de l'enfant. On conclut que la parentalisation se montre comme un risque pour la santé psychique de l'enfant quande elle se constitue comme le moyen privilégié de la relation entre les parents et les enfants.

Mots-clés: développement émotionnel; maturité de l'enfant; parentalité; parentalisation; psychanalyse.

Temosnosdeparado, cadavezmais, emnossa experiência clínica, com uma forma específica de convivência entre pais e filhos, na qual não há clara distinção a respeito de quem se responsabiliza por quem no interior da família. Nessas condições, a dinâmica familiar, caracterizada por variados níveis de hierarquia entre os membros, se transforma em uma relação simétrica e igualitária. Sabemos que algumas funções parentais são insubstituíveis e intransferíveis, especialmente, tendo em vista que cabem aos adultos o cuidado e a responsabilidade pelas crianças. Nesse sentido, a recusa ou a indisponibilidade dos pais em exercer a parentalidade, em virtude de uma significativa regressão ou imaturidade emocional deles, ainda que sejam adultos bem-intencionados, produz um estado de desamparo radical nos filhos. Desse modo, o lugar parental se mostra vazio ou frágil, mesmo que pai e ou mãe estejam presentes no espaço familiar, pois, de fato, se encontram pouco disponíveis para a maternidade e ou paternidade, ocupados com o atendimento das suas próprias necessidades, quer sejam objetivas ou afetivas. Tal indisponibilidade se institui como um campo fértil para a troca de posições entre as funções parentais e as funções filiais, conceituada como parentalização dos filhos; fenômeno frequente, reconhecido e incontestável em inúmeras situações familiares (Boszormenyi-Nagy \& Spark, 2012/1973; Haxhe, 2013; Harrus-Révidi, 2004; Jurkovic, 1997; Le Goff, 1999; Minuchin, Montalvo, Guerney, Rosman, \& Shumer, 1967).

A parentalização dos filhos se define por um processo que se desenvolve no interior da família, a partir do qual uma criança passa a se encarregar das funções parentais, em um determinado contexto sociocultural e histórico. Tais encargos ultrapassam as competências características dos estágios de desenvolvimento infantil, sendo tomados, portanto, de modo prematuro pela criança. As necessidades prementes dos pais (pai ou mãe) são consideradas à custa da desconsideração das necessidades dos filhos. Nessas condições, a conduta regressiva dos progenitores termina por exigir uma conduta progressiva dos filhos, levando a criança a se tornar um adulto em miniatura, adquirindo competências dissonantes com o desenvolvimento infantil. Desse modo, a inversão geracional no interjogo familiar termina por exigir a aceleração dos processos de maturação, exigência paga com a moeda mais cara ao universo infantil: o brincar espontâneo.

Diante disso, o presente estudo tem como objetivo compreender a experiência da criança que adota uma postura parental diante dos adultos importantes para o seu existir. Para atingirmos tal objetivo, realizaremos uma revisão da literatura acerca da problemática da parentalização no âmbito das teorias psicanalíticas e sistêmicas, com foco no desenvolvimento emocional infantil. Inicialmente, pretendemos examinar o estatuto do conceito de parentalização, dos esboços iniciais no campo psicanalítico à consolidação do conceito no campo das psicoterapias de família. Em seguida, vamos nos debruçar na psicodinâmica familiar invertida e nas estratégias de convivência entre os pais e os filhos, a fim de circunscrever a experiência infantil da parentalização. Por fim, interessanos investigar o funcionamento psíquico da criança que sofre vicissitudes tão específicas durante o seu crescimento, com a troca das posições entre pais e filhos. Sustentamos que a parentalização se apresenta como um risco para a saúde emocional da criança quando se consolida como via privilegiada da relação entre pais e filhos.

\section{O Estatuto do Conceito de Parentalização}

Uma das mais antigas referências à noção de parentalização, no que se refere ao aspecto de inversão do papel parental, se encontra em um artigo de Schmideberg (1948), intitulado "Parents as children". Nesse artigo, a psicanalista aponta como alguns pais, em função de experiências altamente emocionais, como os conflitos conjugais, envolvendo perdas significativas, tendem a investir no filho como uma figura parental. Na linha dessas ideias, Mahler e Rabinovitch (1956) observam como a criança pode assumir vários papéis na família, tais como, pacificadores, ajudantes e confidentes, para fortalecer os laços familiares, especialmente, a relação conjugal dos pais. Por essa via, Anna Freud (1965) também sugere que o lugar vazio deixado pela separação do casal conjugal pode levar o filho a preenchê-lo. Nesse contexto, podemos perceber como a parentalização dos filhos se mostra tributária de certa fragilidade narcísica dos pais, os quais encontram dificuldades para arcar com a estrutura e o direcionamento 
familiar. Cabe sublinhar que tais referências iniciais já colocam em evidência um elemento fundamental para a compreensão do conceito de parentalização que consiste no esforço das crianças para assegurar o bem-estar dos seus progenitores, garantindo, assim, um ambiente mais favorável para se habitar.

Apesar de a noção de parentalização dos filhos ter sido forjada no campo psicanalítico, a sua emergência enquanto um conceito definido emerge, essencialmente, no seio das práticas de terapias de família. Em torno dos anos sessenta e setenta, surgem, assim, duas perspectivas fundamentais a respeito da parentalização dos filhos. Inicialmente, o terapeuta de família argentino Minuchin, em conjunto com seus colaboradores, introduz o conceito de "criança parental" em 1967, ao se referir à atribuição de poder parental a uma criança. Poucos anos depois, em 1973, o psiquiatra e terapeuta de família húngaro-americano Boszormenyi-Nagy propõe o termo "parentalização" para designar a distorção subjetiva das relações, onde um dos membros, frequentemente, uma criança, torna-se um pai para o outro. As duas formulações aparecem de forma privilegiada e, intimamente, associadas na literatura sobre o tema, mas guardam algumas nuances, de acordo com a perspectiva teórico-clínica de cada um dos autores. Tais nuances contribuem para o enriquecimento da discussão em voga, como veremos a seguir.

A partir de seus trabalhos com famílias que habitam os guetos (bairros extremamente pobres, com forte presença de imigrantes) da cidade de Nova York, Minuchin et al. (1967) chamam a atenção para as crianças que assumem responsabilidades parentais em um contexto desorganizado e socioeconômico precário. No contexto de famílias caóticas, frequentemente numerosas, os pais exercem uma gestão relativa das suas funções parentais, demonstrando certa autoridade na relação com os filhos, por um lado, e uma indisponibilidade, por outro. Nesse sentido, as crianças, às vezes, podem contar com os pais, às vezes não. Em caso de ausência parental, portanto, os filhos tomariam para si parte da função dos pais. Há, por assim dizer, uma delegação da responsabilidade adulta à criança parental, o que por sua vez, pode ser feito de maneira explícita e consciente ou implícita e inconsciente. Com efeito, atribuir a função parental à criança implica na desorganização dos subsistemas parentais e fraternos e na inversão dos papéis parentais e filiais na família.

$\mathrm{Na}$ linha dessas ideias, Boszormenyi-Nagy, em seu trabalho em "Lealdades invisíveis" (2012/1973), juntamente com Spark, aprofunda o conceito de parentalização. Calcado numa ética relacional, o terapeuta eleva destaca a distorção subjetiva das relações entre pais e filhos como elemento central da problemática da parentalização. Nesse caso, tratase da transformação da criança em um adulto imaginário, de modo que o progenitor passa a tomar a criança como se fosse um igual do ponto de vista geracional. Nota-se aqui que a diferença existente entre as gerações é negada em prol da sustentação da parentalização. Para o autor, até o mais maduro dos adultos possui, em determinadas oportunidades, necessidades regressivas de gratificação, sendo a parentalização uma manobra radical de atualização dessas necessidades na dinâmica familiar. Por esse viés, a conduta regressiva dos pais termina por demandar uma postura progressiva dos filhos, independentemente do despreparo infantil para tanto. Desse modo, parece-nos evidente que a parentalização se institui num sistema familiar no seio do quais os pais estão eles mesmo sofrendo carências afetivas ou com falta de definição das fronteiras geracionais.

Do ponto de vista dos pais, podemos reconhecer a presença de alguns fatores históricos e outros conjecturais subjacentes ao fenômeno da parentalização (Haxhe, 2013; Le Goff, 1999). No que se refere aos fatores históricos, Harrus-Révidi (2004) afirma que a "criança-adulta" se constitui a partir de um adulto imaturo, no sentido de que ele está orientado em torno das suas próprias necessidades. A autora sustenta que esses pais imaturos não sabem se adaptar à criança, na medida em que eles também não obtiveram tal adaptação dos seus progenitores. Por essa via de abertura, Olson e Gariti, (1993) também se referem aos pais das crianças parentalizadas com base no não atendimento das suas próprias necessidades pelos seus pais, ou seja, a própria infância dos pais não teria sido, assim, considerada pelos seus progenitores. Dando relevo ao aspecto transgeracional da parentalização, Bekir, Mclellan, Childress e Gariti (1993) apontam ainda que muitos dos pais que demandam uma postura parental dos seus filhos também foram parentalizados por seus pais quando crianças.

Existem também alguns fatores mais conjecturais, observados, sobretudo, no que diz respeito ao exercício da parentalidade nas novas configurações familiares na contemporaneidade (Féres-Carneiro, 2011). Por esse viés, podemos nos referir, por exemplo, aos pais separados ou recasados que se encontram muito absorvidos pelas suas vidas afetivas instáveis, ocupados em reconstruir suas vidas conjugais (Haxhe, 2013; Heck \& Janne, 2011). Cabe sublinhar que essas novas configurações também costumam demandar esforços pessoais mais substanciais da parte do conjunto dos membros. Trata-se, então, de situações familiares, muitas vezes, na ausência do outro par do casal parental, nas quais a parentalização se apresentaria potencialmente, isto é, como um recurso cotidiano necessário para o funcionamento da família, tornando-se, inclusive, um fator de resiliência familiar (Walker \& Lee, 1998). Nessa direção, as vinculações externas do núcleo familiar, isto é, a rede de apoio da família, podem suavizar o compromisso de ajuda mútua entre os seus membros. Convém ressaltar, contudo, que tais fatores nos oferecem apenas pistas para discriminar a lógica familiar invertida, considerando que a parentalização se institui, efetivamente, 
quando os adultos delegam a função parental às crianças.

Nesse sentido, é importante precisar que a parentalização não se circunscreve de forma incondicional no campo da patologia ou da disfunção relacional. A esse propósito, Boszormeny-Nagy (2012/1973) chega a afirmar que provavelmente certo grau de parentalização inconsciente seja parte constituinte da atitude dos progenitores em relação aos seus sucessores. Nessa medida, Le Goff (1999) sublinha que a parentalização é um risco inerente à responsabilidade parental e à filiação, podendo ser encontrado em todas as famílias, independentemente de qualquer relação patológica. Para os autores, a inversão geracional não é, portanto, sinônimo de padecimento psíquico, podendo favorecer, inclusive, a identificação da criança com a imagem de uma boa figura parental, algo que ela pode vir a ser no futuro. Assim sendo, tratar-se-ia da construção de um contexto familiar de solidariedade e confiança, bastante funcional.

A nosso ver, a vivência de um filho que se ocupa, de modo delimitado e provisório, do cuidado dos pais ou da família em geral é, absolutamente, diferente, da vivência de um filho instado a adotar uma postura parental, a fim de satisfazer a dependência de adultos regredidos e imaturos. Nessa linha de pensamento, em determinadas circunstâncias, a necessidade dos pais de parentalizar o filho se mostra extremamente perniciosa para a criança, repercutindo, sobremaneira, nos seus processos de maturação. Entendemos que a parentalização assume um sentido patológico, na medida em que interfere nas possibilidades de crescimento da criança, sobretudo, quando a inversão é negada ou desmentida pelos pais. Nessa direção, os encargos parentais, tomados prematuramente pela criança, ultrapassam, em níveis diversos, as competências características dos estágios de desenvolvimento emocional infantil, podendo acelerar, por conseguinte, o ritmo da sua maturação.

\section{A Experiência Infantil da Parentalização}

Não nos restam dúvidas quanto à existência de bases relacionais para o processo de parentalização dos filhos. Contudo, se por um lado, a parentalização se institui como um processo externo de distorção da dinâmica relacional familiar, por outro lado, expressa um processo interno na experiência individual de cada membro da família. Para além das pautas de interação na família, podemos afirmar que o olhar intrapsíquico para tais questões intersubjetivas se apresenta como um diferencial no trabalho clínico com as crianças parentalizadas. Desse modo, vamos procurar dar relevo à experiência infantil da parentalização, a qual inclui um funcionamento adulto antecipado. $\mathrm{O}$ ponto que nos interessa destacar é que tal delegação de responsabilidade se constitui como uma demanda para a qual a criança não tem maturidade para satisfazer.

De início, parece-nos importante precisar, de acordo com Boszormenyi-Nagy (2012/1973), que a criança parentalizada é eleita não apenas pelos pais, mas com base em toda evolução das relações familiares. Em geral, se pensa em uma escolha de um dos pais ou do casal parental, mas devemos considerar, também, os membros da fratria e o modo de ser da própria criança. Nesse sentido, a criança escolhida para o papel parental, habitualmente, demonstra uma maior empatia com as necessidades de seus progenitores. Vale acrescentar que esse papel não precisa ser necessariamente atribuído a apenas uma criança, podendo ser compartilhado entre os irmãos. Para avaliar a dimensão da experiência infantil da parentalização, devemos levar em conta a rigidez, a duração, a amplitude e alguns fatores de proteção, como a existência de outras figuras de cuidado para a criança. Seja como for, quanto mais sobrecarga física e emocional se imputa à criança, mais custosa se revela a parentalização.

Com efeito, a conduta pouco cuidadosa e responsável de alguns progenitores demanda que as crianças, mesmo bem pequenas, assumam diversos papéis na família. Por esta via de abertura, Boszormenyi-Nagy (2012/1973) postula a existência de diferentes papéis ligados à parentalização. Destaca o "papel de cuidador" ao se referir às crianças que exercem as tarefas de cuidado manifestas ou aquelas que se exercem de forma mais mascarada. A título de ilustração, podemos evocar o caso de uma criança que é levada a tomar conta dos irmãos mais novos por conta de uma significativa indisponibilidade parental. Ou ainda, o caso de uma criança que é levada a cuidar da mãe profundamente deprimida, animando-a constantemente. $\mathrm{O}$ autor chama a atenção, também, para a criança que desempenha o "papel de sacrifício", uma espécie de mártir, exercendo, assim, um certo controle na dinâmica familiar. Nesse caso, podemos considerar um filho de pai alcoolista, convocado a se conduzir de maneira mais adulta que o seu pai, por exemplo. Por fim, o terapeuta aborda o "papel neutro" adotado silenciosamente pela criança parentalizada. Tratase aqui da criança bem-comportada, que não exige qualquer trabalho dos pais, comumente, descrita como agradável, fácil de educar, pouco exigente.

Parece-nos profícuo e apropriado supor que tais papéis não se apresentam de forma estanque no cotidiano familiar, sendo executados, e por vezes sendo superpostos, em conformidade com as especificidades das demandas parentais. Em relação às demandas, cabe diferenciar as necessidades parentais em termos de sustentação instrumental e física ou amparo afetivo, sendo que esse último se configura como um maior sacrifício para as crianças. Nessa mesma direção, Jurkovic (1997) pontua a existência de duas funções constituintes da parentalização: a função emocional e a função instrumental. Trata-se, sem dúvida, de duas funções associadas e que se influenciam 
mutualmente.

$\mathrm{Na}$ linha dessas considerações, Le Goff (1999), distingue dois tipos de parentalização: a parentalização construtiva e a parentalização destrutiva. Tais tipos mantêm uma relação complexa, tendo em vista que toda experiência de parentalização envolve aspectos negativos e positivos. $\mathrm{Se}$ os efeitos positivos permanecem em primeiro plano, a parentalização se torna uma experiência a favor do movimento de maturação que permitirá à criança enfrentar as dificuldades da vida com mais confiança e recursos. Nesse caso, a relação com os pais se mostra suficientemente boa. Em contraposição, se os fatores negativos são imperativos, a criança será exposta ao desamparo e à vulnerabilidade, constituintes fundamentais da subjetividade do ser humano, experiência traumática, por excelência.

Em relação à parentalização construtiva, Le Goff (1999) considera como fundamental que as responsabilidades delegadas à criança não sejam esmagadoras em relação à sua maturidade. Além disso, o fato de a criança contar com outros adultos ou membros da fratria também se mostram positivos. Assim, quando se trata de uma experiência de tomada de responsabilidade, por um período determinado e transitório, sob alguma supervisão e apoio, a criança pode tirar algum proveito disso em favor da sua evolução. A parentalização destrutiva, por sua vez, diz respeito à criança sobrecarregada de tarefas que ultrapassam suas competências. Nessas condições, os pais se comportam como crianças em relação ao filho, de modo que as necessidades infantis são negligenciadas. Não há sustentação da família de origem dos progenitores ou rede de apoio. Trata-se de uma manobra de exploração manifesta, com severas implicações para o desenvolvimento emocional da criança.

Para Le Goff (1999), a parentalização construtiva pode evoluir na direção de uma relação entre pais e filhos não parentalizada ou no sentido da parentalização destrutiva. Seja como for, o reconhecimento dos pais pelos esforços dos filhos atenuam, sobremaneira, os efeitos destrutivos da inversão geracional. Nesse sentido, Boszormeny-Nagy e Krasner (1986) afirmam que a parentalização é o inverso do justo reconhecimento da privação do direito natural de ser criança, a qual o filho se submete.

Cabe acrescentar que a parentalização pode engendrar, às vezes, algum ganho secundário para a criança, na medida em que proporciona certo lugar de importância e poder na família. A esse propósito, Jurkovic (1997) chama a atenção para a sensação de "grandiosidade" experimentada pela criança que se torna pais (pai/mãe) de seus progenitores. Nesse sentido, algumas crianças não apresentam queixas manifestas em relação à exploração da sua maturidade, de forma que a parentalização funciona em proveito de todos os membros da família. Porém, as repercussões para o desenvolvimento emocional podem surgir anos mais tarde, especialmente, na adolescência, às voltas com as tarefas de diferenciação e individuação, tão proeminentes nesse estágio.

Certamente, as pautas de relações subjacentes à parentalização ilustram como funcionam os "compromissos de lealdade" na família (Boszormenyi-Nagy, 2012/1973). É como se tantos os pais quanto o filho almejassem que a inversão no sistema de lealdade promovesse um funcionamento adequado da família, ou seja, como se a inversão pudesse servir para modelar melhor as relações entre os membros. Por essa perspectiva, nos parece evidente como a conduta regressiva dos progenitores pode engendrar condutas progressivas nos filhos. Das demandas infantis ao dom parental, as crianças tornam-se pais de seus próprios pais. Convém sublinhar que a palavra dom é utilizada por nós para realçar, não o sentido de um suposto dote ou qualidade natural, mas o esforço da vontade desprendido pela criança para desempenhar a função parental.

\section{Repercussões da Parentalização no Desenvolvimento Emocional Infantil}

Com efeito, a criança parentalizada se encontra submetida a uma exigência de evolução, não se permitindo formular demandas legítimas aos pais. Muito pelo contrário, ela transforma as demandas infantis em dom parental, no sentido da aquisição de competências cabíveis aos pais. Nessas condições, a criança quando parentalizada amadurece às pressas, atribuindo-se funções adultas, justamente, pelo imperativo de não ser mais criança, com as necessidades que lhes são peculiares. Considerando a imaturidade primitiva do bebê humano (Freud, 1905/1996), podemos dimensionar como as falhas parentais na satisfação dos cuidados infantis podem engendrar desproteção, instabilidade e ameaça de colapso psíquico, exigindo, muitas vezes, o acionamento de defesas radicais por parte da criança. Levando em conta que a criança não tem condições para produzir modificações no ambiente parental de maneira aloplástica, dada a sua pouca idade, não the resta outra alternativa, senão transformar-se a si mesmo de modo autoplástico, organizando um novo modo de ser adaptado à psicodinâmica familiar por meio da parentalização.

Muitos autores (Boszormenyi-Nagy \& Spark, 2012/1973; Heck \& Janne, 2011; Minuchin et al., 1967) abordam o ponto de vista das relações familiares da parentalização, sem aprofundar, contudo, a compreensão dos aspectos intrapsíquicos, isto é, as repercussões da inversão geracional no desenvolvimento emocional infantil. Por essa via de abertura, buscamos refletir sobre tais repercussões na subjetividade da criança, a partir das contribuições de um autor fundamental da psicanálise: o psicanalista húngaro Sandor Ferenczi. Vamos lançar mão aqui de duas noções cruciais da sua obra para o entendimento do mundo interno da criança parentalizada: a metáfora do "bebê sábio" e o conceito de "progressão traumática". 
Em toda a sua obra, Ferenczi afirma categoricamente a necessidade da adaptação da família à criança e não o inverso. $\mathrm{O}$ autor defende a importância de o novo integrante se sentir bem-vindo no ambiente familiar, uma vez que a relação com o mundo se inaugura por meio das trocas interpessoais com as figuras parentais (Ferenczi, 1928/1992). O cuidado parental se realiza, então, a partir da adaptação às necessidades da criança na proporção adequada e suficiente para ela e não em função dos anseios parentais. Os pais não devem impor suas próprias demandas ao filho. Assim, é importante que os pais respeitem a diferença existente entre os modos de relação da criança e do adulto.

Para Ferenczi, o importante não é tanto o que ocorre de modo episódico na vida da criança, mas sim o fato de a criança dispor ou não de alguém em quem confiar. Considerando a imaturidade primitiva e a dependência da criança em relação aos pais, apreendemos como as falhas das figuras parentais no exercício de suas funções podem apresentar um caráter traumático; exigindo, muitas vezes, o acionamento de defesas radicais para assegurar a sobrevivência psíquica. É importante notar que, muitas vezes, as defesas se organizam antes mesmo de uma estabilidade subjetiva, levando em conta os estágios da maturação infantil. Nesse contexto, as falhas parentais representam o desencontro entre aquilo de que a criança precisa do adulto e a surpresa pelo que sobrevém do adulto. $\mathrm{O}$ fator determinante reside na ausência de um adulto disponível para o cuidado. São figuras parentais que, por indiferença, atribulações, inabilidade, incompreensão, imaturidade, histórias familiares, ou mesmo, loucura, precisam receber mais do que dar.

Nesse sentido, Ferenczi introduz a metáfora do bebê sábio num pequeno artigo intitulado "O sonho do bebê sábio" (2011/1923). O sonho coloca em cena o desejo infantil de suplantar os "grandes" em sabedoria, desejo que, por sua vez, inverte a situação na qual a criança se encontra em relação ao adulto. Para Ferenczi, as crianças se tornam sábias sob a pressão da urgência traumática. Trauma aqui entendido como cuidado insuficiente, falho, errante nos estágios de dependência absoluta dos pais. Essa sabedoria corresponde a um mecanismo de defesa contra o colapso emocional, a partir do qual as crianças podem manifestar faculdades potenciais, faculdades virtualmente pré-formadas. Vale insistir que quando os pais se mostram incapazes de se adaptar à criança, quem se adapta aos pais é a criança. Apressando o ritmo da maturação infantil, desenvolve, então, competências adultas, para além da sua idade.

A referida defesa pode ser melhor compreendida em termos de uma "progressão traumática" ou "prematuração patológica". A criança forjaria, portanto, uma sabedoria intelectual como a de umfilósofo compreensivo, inteiramente objetivo, mas sem que se estabeleça ligação entre o mundo objetivo e a subjetividade, entre os pensamentos e os afetos. O intelecto se transforma num substituto do cuidado parental. Desse modo, a inteligência se ocupa do autocuidado, livrando a criança do perigo de estar à mercê de adultos pouco confiáveis, com os quais não se sente em segurança. $\mathrm{O}$ autocuidado recai em um cuidado dos pais insuficientes, o que se constitui como filiação invertida: a criança se torna pai e mãe ou, mais precisamente, pai e mãe de seus pais. A ideia aqui é de uma performance parental, um faz-de-conta que dá conta, tentativa desesperada da criança para criar uma atmosfera favorável ao seu próprio crescimento.

É importante salientar que não há um objetivo altruísta nesta tomada megalômana de responsabilidade por parte da criança em relação aos pais (pai ou mãe), mas, uma tentativa de assegurar sua própria vida no interior da família. No contexto das falhas ambientais precoces, podemos testemunhar, então, o desenvolvimento de uma espécie de atividade meteorológica, como bem ressalta Rabain (2010), por meio da qual as crianças estudam as variações do ambiente familiar para adaptar-se adequadamente, tal como os meteorologistas estudam o céu para predizer o tempo que vai fazer. Considerando o árduo esforço envolvido para se encarregar do cuidado dos seus pais, a criança termina por renunciar às suas necessidades infantis em prol da postura parental. O avanço dos processos de maturação exige uma alta dose de sacrifício, paga com a moeda mais cara ao universo infantil: o brincar espontâneo (Winnicott, 1971/1975), campo privilegiado de experiências enriquecedoras e indispensáveis para o desenvolvimento emocional sadio da criança.

\section{Considerações Finais}

$\mathrm{Na}$ clínica, temos nos defrontado, frequentemente, com crianças que apresentam posturas adultas, exercendo funções parentais na dinâmica familiar, num cenário atual de adultização da infância e de crescentes exigências de performance. Não raro, apresentam entraves nainteraçãocom outras crianças, tornando-se solitárias e sem pertencimento. Em geral, trata-se de crianças particularmente perspicazes e compassivas, mostrando desenvoltura e relativa independência no desempenho das tarefas cotidianas, em outras palavras, crianças muito bem-comportadas, tanto no sentido de portar-se quanto de conter-se. Essas crianças, frequentemente, obtêm um reconhecimento acadêmico exemplar, exibindo uma autocrítica severa diante do menor indício de fracasso. Uma das fontes de sofrimento infantil mais evidentes é o esgotamento emocional em virtude dos esforços intensos para representar de forma prematura a função parental no sistema familiar. Com efeito, a criança parentalizada encontra dificuldades para viver uma vida apropriada para sua idade.

Dentro desse contexto, a inversão geracional no 
interjogo familiar configura-se como um risco para a saúde psíquica da criança quando se consolida como via privilegiada da relação entre pais e filhos. O processo de inversão geracional, nas múltiplas configurações familiares, está cada vez mais presentes nos dias de hoje. Marcada, especialmente, pela distorção entre as fronteiras geracionais, o processo de parentalização envolve não apenas certo número de competências e tarefas desenvolvidas pela criança, custosas por certo, mas uma ética relacional, na qual se encontram em jogo os vínculos de confiança entre pais e filhos.

Torna-se, assim, cada vez mais importante o desenvolvimento de estudos que aprofundem a compreensão das repercussões da parentalização no desenvolvimento emocional dos filhos, especialmente, com foco na articulação das teorias psicanalíticas e sistêmicas. Considerando que os trabalhos que abordam esta questão ainda são muito escassos, especialmente na literatura nacional, tal aprofundamento, certamente, fornecerá subsídios importantes para a prática clínica contemporânea e para o campo de pesquisa das relações entre pais e filhos.

\section{Referências}

Bekir, P., McLellan, T., Clhildress, A., \& Gariti, P. (1993). Role reversal in families of substance misusers: a transgeracional phemonen. The International Journal of the Addictions 28, 613-630.

Boszormeny-Nagy, I., \& Krasner, B. (1986). Between give and take. New York: Brunner/Mazel.

Boszormenyi-Nagy, I., \& Spark G. (2012). Lealtades invisibles. Buenos Aires: Amorrortu. (Originalmente publicado em 1973)

Ferenczi, S. (1992). A adaptação da família à criança. In S. Ferenczi, Obras Completas (Psicanálise III, pp. 1-13). São Paulo: Martins Fontes LTDA. (Originalmente publicado em 1928)

Ferenczi, S. (2011). O sonho do bebê sábio. In S. Ferenczi, Obras Completas (Psicanálise III, pp. 223-224). São Paulo: Editora WMF Martins Fontes LTDA. (Originalmente publicado em 1923)

Ferés-Carneiro, T. (2011). Casal e família: Permanências e rupturas. São Paulo: Casa do Psicólogo.

Freud, A. (1965). Normality and pathology in childhood. New York: International Universities Press.

Freud, S. (1996). Três ensaios sobre a teoria da sexualidade.
In S. Freud, Edição Standard Brasileira das Obras Psicológicas Completas de Sigmund Freud (Vol. VII, pp. 119-231). Rio de Janeiro: Imago. (Originalmente publicado em 1905)

Haxhe, S. (2013). L'enfant parentifié et as famille. Toulouse: Éditions érés.

Harrus-Révidi, G. (2004). Parents immatures et enfantsadultes. Paris: Petit Bibliothèque Payot.

Heck, L., \& Janne, P. (2011). Vous avez dit 'parentification'? Revue du concept et réactualisation selon les derniers résultats empiriques. Thérapie Familiale, 32 (2), 253274.

Jurkowic, G. (1997). Lost childhoods. The plight of the parentified child. New York: Brunner-Routledge.

Le Goff, J-F. (1999). L'enfant, parent de ses parents. Parentification et thérapie familiale. Paris: Harmattan.

Mahler, M. S., \& Rabinovitch, R. (1956). The effects of marital conflict on child development. In V. E. Eisenstein (Ed.), Neurotic interaction in marriage (pp. 44-56). New York: Basic Books.

Minuchin, S., Montalvo, B., Guerney, B., Rosman, B., \& Shumer, F. (1967). Families of the slums. An exploration of their structure and treatment. New York: Basic Books.

Olson, M., \& Gariti, P. (1993). Symbolic loss in horizontal relating: defining the role of parentification in addictive relationships. Contemporary Family Therapy, 15, $197-$ 208.

Rabain, J-F. (2010). Freud ou Winnicott? La place du père et de la mère dans la construction psychique. Mag Philo. Freud, le retour. Retrieved from http://www. cndp.fr/ magphilo/index.php?id=28

Schmideberg, M. (1948). Parents as childrens. Psychiatric Quarterly Supplement, 22, 207-218.

Walker, J., \& Lee, R. (1998). Uncovering strenghts of children of alcoholic parents. Contemporary family therapy, 20 (4), 521-533.

Winnicott, D. W. (1975). O brincar e a realidade. Rio de Janeiro: Imago. (Originalmente publicado em 1971) 
Endereço para correspondência:

Renata Mello

Endereço: Rua José Roberto Macedo Soares, 12/101,

Gávea. Rio de Janeiro/RJ, CEP: 22470-100.

E-mail: renatamello@gmail.com

Endereço para correspondência:

Terezinha Féres-Carneiro

Endereço: Rua Marquês de São Vicente, 225, Gávea. Rio de Janeiro/RJ, CEP: 22453-900.

E-mail: teferca@puc-rio.br

Endereço para correspondência:

Andrea Seixas Magalhães

Endereço: Rua Marquês de São Vicente, 225, Gávea. Rio de Janeiro/RJ, CEP: 22453-900.

E-mail: andreasm@puc-rio.br 